\title{
Effect of myeloperoxidase modified LDL on bovine and human aortic endothelial cells
}

\author{
GHADIR EL SAMAD $^{1}$, SAMER BAZZI $^{1}$, MARC KARAM $^{1}$, \\ KARIM ZOUAOUI BOUDJELTIA ${ }^{2}$, LUC VANHAMME ${ }^{3}$ and JALIL DAHER $^{1}$ \\ ${ }^{1}$ Department of Biology, Faculty of Sciences, University of Balamand, Tripoli 100, Lebanon; \\ ${ }^{2}$ Laboratory of Experimental Medicine (ULB 222 Unit), CHU de Charleroi, A. Vésale Hospital, \\ Université Libre de Bruxelles, Montigny-le-Tilleul 6110; ${ }^{3}$ Laboratory of Molecular Biology of Inflammation, \\ IBMM, Faculty of Sciences, Université Libre de Bruxelles, Gosselies 6041, Belgium
}

Received April 3, 2019; Accepted August 6, 2019

DOI: $10.3892 /$ etm.2019.8109

\begin{abstract}
Cardiovascular disease associated with atherosclerosis is a leading cause of death worldwide. Atherosclerosis is primarily caused by the dysfunction of vascular endothelial cells and the subendothelial accumulation of oxidized forms of low-density lipoproteins (LDL). Early observations have associated fibrin deposition with atheroma plaque formation, which has led to the proposition that a decrease in endothelial cell fibrinolysis may negatively influence atherogenesis. It has been recently demonstrated that myeloperoxidase modified LDL (MoxLDL) decreases endothelial cell profibrinolytic capacity in real-time. The present study investigated the role of MoxLDL in endothelial cell dysfunction by determining the molecules that may be involved in decreasing the fibrinolysis of human aortic endothelial cells (HAEC). Accordingly, reverse transcription-quantitative PCR was performed to screen for the differential expression of major genes that are implicated in the fibrinolytic process. In addition, the response of the latter cell type to MoxLDL was compared with bovine aortic endothelial (BAE) cells. Furthermore, the effect of the treatment on the generation of reactive oxygen species (ROS) was also determined. Although the current study did not demonstrate an association between MoxLDL treatment and a change in the expression of any major fibrinolytic factor in HAEC, a discrepancy between HAEC and BAE cells with respect to their response to modified LDL treatment was observed. The result have also demonstrated that MoxLDL does not increase ROS generation in HAEC as opposed to the other major type of modified LDL, cupper oxidized LDL (CuoxLDL) that was reported to exhibit a positive effect at this level. The
\end{abstract}

Correspondence to: Dr Jalil Daher, Department of Biology, Faculty of Sciences, University of Balamand, 108 Fares Road, Deir El Balamand, El-Koura, Tripoli 100, Lebanon

E-mail: jalil.daher@balamand.edu.lb

Key words: atherosclerosis, myeloperoxidase oxidized low-density lipoprotein, fibrinolysis, endothelial cells, human aortic endothelial cells, bovine aortic endothelial cells present study provided important insight into the different effects of MoxLDL and CuoxLDL in endothelial cells, which may aid future studies to determine the various signaling pathways that are promoted by these molecules. The results of the present study may be utilized to identify potential molecular drug targets for the treatment of atherosclerosis.

\section{Introduction}

Cardiovascular diseases (CVDs) are a wide spectrum of diseases affecting the heart and blood vessels. This spectrum includes mainly coronary heart disease (CHD) and cerebrovascular disease (1). Atherosclerosis, the culprit cause of myocardial and cerebral infarction, is the principle agent of mortality and morbidity worldwide (2). Atherosclerosis is a cardiovascular disease marked by the dysfunction of the endothelium, formation of lipid-laden plaques, and narrowing and hardening of the blood vessels. Over the centuries, many hypotheses were postulated to explain the mechanism behind the initiation and development of the atherosclerotic lesions. The three main theories are the lipid theory, the oxidation hypothesis of atherogenesis and the response-to-injury inflammatory hypothesis. The cornerstone focus of the oxidative hypothesis is that specifically oxidized low density lipoproteins (LDL) generated by myeloperoxidase pathways are injurious to the arterial cell wall as reported by Chilsom and colleagues in 1979. The inflammatory response-to-injury hypothesis is regarded as the refinement of the previous theory; during the 19th century, the pathologist Rudolf Virchow described atherosclerosis as a chronic inflammation (3). This hypothesis proposes that injury to the endothelium and its dysfunction, which leads to fibrin deposition, are the initiating events along with its increased permeability to modified lipoproteins (4). Oxidation of low density lipoproteins have been of major interest since Steinberg et al showed that native LDL does not accumulate in macrophages whereas modified lipoproteins do (5).

Oxidized LDL (oxLDL) unlike the native LDL (nLDL) was shown to initiate and trigger the inflammatory process of the disease (6). Several candidates were then proposed to elucidate LDL modification including myeloperoxidase (MPO). Ample studies showed the responsibility of MPO in atherogenesis 
in humans. Immunohistochemical and biochemical analyses conducted by Daugherty et al (7) co-localized MPO and its products within human atheromatous plaques (7-9). On the same note, it has been shown that individuals with a deficiency in the MPO enzyme are less prone to develop CVDs on the long term. Another relationship appears in which increased systematic levels of MPO indicates the presence of coronary artery disease (CAD) (10). A major function of the vascular endothelium is the fine-tuning of the delicate components of the coagulation and fibrinolytic systems. It maintains anticoagulant and antithrombotic environment by releasing a variety of molecules that regulate blood hemostasis assuring a profibrinolytic state (11). Accordingly, the endothelium secretes major fibrinolytic factors including tissue plasminogen activator (tPA), urokinase plasminogen activator (uPA), and plasminogen activator inhibitor-1 (PAI-1) and express specific receptors that binds these factors supporting a fibrinolytic environment (12). Also, as mentioned above, early observations have correlated fibrin deposition with atheroma plaque formation. This led to the proposition that a decrease in fibrinolysis in endothelial cells may negatively influence atherogenesis. In parallel, recent studies have also revealed that patients with atherosclerosis exhibited a hypofibrinolytic phenotype (13). Since it has been previously confirmed that MoxLDL decreases EA.hy926 profibrinolytic capacity in real-time without delineating the mechanisms by which this modified LDL can alter pericellular fibrinolysis (14), we tried in the present study to perform a preliminary dissection of the molecules that might be involved in decreasing fibrinolysis by using primary HAEC as a model. The study also included an ephemeral comparison regarding the disparate effect of MoxLDL on two different primary cultures of endothelial cells, bovine aortic endothelial cells and human aortic endothelial cells, as well as its effect on reactive oxygen species (ROS) generation in the latter model.

\section{Materials and methods}

Cell culture. BAE cells were cultured in Dulbecco's Modified Eagle's Medium-AQ (DMEM-AQ, Sigma Aldrich) supplemented with $10 \%$ heat inactivated fetal bovine serum (FBS; Sigma Aldrich), and $1 \%$ penicillin/streptomycin mixture. HAEC's were cultured in EBM-2 Basal Medium supplemented with human epidermal growth factor (hEGF), vascular endothelial growth factor (VEGF), R3-insulin-like growth factor-1 (R3-IGF-1), ascorbic acid, hydrocortisone, human fibroblast grow th factor-beta (hFGF- $\beta$ ), FBS, and gentamicin/amphotericin-B (GA) (Lonza). Cells were maintained at $37^{\circ} \mathrm{C}$ in a humidified $5 \% \mathrm{CO}_{2}$ incubator. BAE cells and HAEC were used between passages 5-9.

In vitro treatment of $B A E$ and HAEC. BAE cells and HAEC were seeded in 6 -well plates at a density of $5 \times 10^{5}$ cells/well in triplicates. Cells were either left untreated or treated with nLDL $(100 \mu \mathrm{g} / \mathrm{ml})$ or with MoxLDL $(25,50$, or $100 \mu \mathrm{g} / \mathrm{ml})(15,16)$. Cell morphology was monitored after treatment and images (x200 magnification) were captured using a phase contrast inverted microscope (Leica).

Recombinant MPO preparation. Recombinant MPO was prepared as described previously (14). Briefly, in order to express MPO, a recombinant plasmid that codes for prepromyeloperoxidase was constructed and named pNIV2703. This plasmid contains an MPO fragment coding for amino acid 11 in the putative signal sequence to amino acid 696. The pNIV2703 expression vector was transfected into $\mathrm{CHO}$ cells by electopermeabilization. Cell supernatants were recovered to assay the production level and the enzymatic activity of secreted molecules. Each batch solution was characterized by its activity $(\mathrm{U} / \mathrm{ml})$, protein concentration $(\mathrm{mg} / \mathrm{ml})$, and specific activity.Peroxidative activity was determined using $o$-dianiside as the substrate. Protein concentration was measured using the Lowry assay, with ovalbumin as a standard. Each batch was checked for endotoxin using the endotoxin detection kit (Lonza). Concentration was always less than $100 \mathrm{pg} / \mathrm{ml}$, which, taking into account the final dilution of the MPO-treated LDL fraction, would contribute a final concentration of less than $0.1 \mathrm{pg} / \mathrm{ml}$ to the MoxLDL supplemented medium added to the cells.

Isolation of $n L D L$ and MoxLDL preparation. $\mathrm{nLDL}$ was isolated and MoxLDL prepared as previously described (14); lipoprotein particles were isolated from plasma from sterile blood pouches using density-gradient ultracentrifugation. The nLDL fraction ( $d=1.019-1.063)$ was stored under nitrogen at $4^{\circ} \mathrm{C}$ in the dark and oxidized according to the procedure described below: Prior to oxidation, nLDL was gel filtered (PD-10 column, Pharmacia) and $1.6 \mathrm{mg}$ of native LDL was oxidized by 2.1 chlorinating units of recombinant MPO, to generate MoxLDL in the presence of $1 \mathrm{mM} \mathrm{H}_{2} \mathrm{O}_{2}$ in $2 \mathrm{ml}$ phosphate buffered saline (PBS) at $\mathrm{pH} 6.5$ for $5 \mathrm{~min}$. LDLs were desalted again after MPO treatment. Protein concentration was measured by the Lowry assay, using ovalbumin as protein standard.

RNA extraction from BAE cells and HAEC. Cells were treated as indicated above and then harvested for total RNA extraction. RNA was extracted using the RNeasy plus mini kit (Qiagen) according to manufacturer's instructions. RNA extracts from different samples were analyzed by spectrophotometry. Absorbance values (A) were recorded at two wavelengths, (260 and $280 \mathrm{~nm}$ ) to assess purity (A260/A280) and measure the concentration (A260) of extracted RNA.

Reverse transcription of RNA. Extracted RNA was reverse transcribed to a complementary DNA (cDNA) using QuantiTect reverse transcription kit according to manufacturer's instructions (Qiagen). Briefly, genomic DNA (gDNA) contaminants were eliminated by incubating extracted RNA in gDNA wipeout buffer (Qiagen) at $42^{\circ} \mathrm{C}$ for $2 \mathrm{~min}$. Then reverse transcription was performed by incubating samples with master mix (reverse transcriptase (RT), RT primer mix, and RT buffer; Qiagen) at $42^{\circ} \mathrm{C}$ for $15 \mathrm{~min}$ and later inactivated at $95^{\circ} \mathrm{C}$ for $3 \mathrm{~min}$.

Reverse transcription-quantitative PCR (RT-qPCR). RT-qPCR was performed using SYBR-Green (Qiagen), on a Real-time Systems (Bio-Rad). $20 \mu \mathrm{l}$ of reaction was added in each well containing: $1 \mu \mathrm{g}$ cDNA, $1 \mu \mathrm{l}$ of $10 \mu \mathrm{M}$ forward and reverse primers (Table I; Sigma), and $10 \mu 1$ Sybr Green. The cycling conditions were: $95^{\circ} \mathrm{C}$ for $3 \mathrm{~min}, 40$ cycles of $95^{\circ} \mathrm{C}$ for $10 \mathrm{~s}$, 
Table I. Primer sequences for the genes of interest.

\begin{tabular}{lll}
\hline Gene & \multicolumn{1}{c}{ Forward } & \multicolumn{1}{c}{ Reverse } \\
\hline tPA & 5'-CCGGCTACGGCAAGCA-3' & 5'-TGGATGGGTACAGTCTGACATGA-3' \\
uPA & 5'-CCGCTTTCTTGCTGGTTGTC-3' & 5'-TATTGTCGTTCGCCCTGGTG-3' \\
uPAR & 5'-GGTGACGCCTTCAGCATGA-3' & 5'-CCCACTGCGGTACTGGACAT-3' \\
tPAR & 5'-TGGATGGGAGACAATCTGTA-3' & 5'-TGCCCTCGATTAAAGTCTTG-3' \\
PAI-1 & 5'-CAGACCAAGAGCCTCTCCAC-3' & 5'-ATCACTTGGCCCATGAAAAG-3' \\
FXIII A1 & 5'-CCAGATTGACTTCAACCGTCCC-3' & 5'-GACACCAGCAAAAACCCAACACTGG-3' \\
GAPDH & 5'-AAATCCCATCACCATCTTCC-3' & 5'-TCACACCCATGACGAACA-3'
\end{tabular}

tPA, tissue plasminogen activator; uPA, urokinase plasminogen activator; uPAR, urokinase plasminogen activator receptor; tPAR, tissue plasminogen activator receptor; PAI-1, plasminogen activator inhibitor-1; FXIII A1, fibrin-stabilizing factor.

and $60^{\circ} \mathrm{C}$ for $30 \mathrm{~s}$. Each reaction was performed in triplicate and GAPDH was used as a reference gene for normalization. Relative gene expression levels and resulting fold changes were calculated using the comparative $2^{-\Delta \Delta C q}$ method (17). Primers sequences for genes of interest were selected from the RTPrimerDB online real-time PCR primer database (rtprimerdb.org) and verified using the online NCBI BLAST tool.

Analysis of BAE cell viability. Propidium iodide (PI) cell viability assay was used to assess the viability of BAE cells following treatment as indicated above. BAE cells were washed once with PBS and detached by incubation with accutase cell detachment solution (Thermo) at $37^{\circ} \mathrm{C}$ for $2 \mathrm{~min}$. Both detached and floating cells were then collected and resuspended in $1 \mathrm{X}$ binding buffer solution (BD Biosciences) and stained with PI (BD Biosciences) for $15 \mathrm{~min}$ at room temperature in the dark. Samples were run on a FACSCalibur flow cytometer (BD Biosciences) and data were analyzed using CellQuest Pro software version 5.1 (BD Biosciences). BAE cells were identified by their forward-scatter (FSC) and side-scatter (SSC) properties. Viable and dead cell populations were identified as PI- and PI+ cells, respectively (18-20). A total of 10,000 single cell events were measured for each sample.

Measurement of ROS generation by HAEC. ROS production by HAEC was assessed following treatment as indicated above using the radical-sensitive fluorescent probe, 2,7-dichlorodihydrofluorescein diacetate $\left(\mathrm{H}_{2} \mathrm{DCFDA}\right.$; Molecular Probes). HAEC were washed once with PBS and detached by incubation with accutase cell detachment solution at $37^{\circ} \mathrm{C}$ for $2 \mathrm{~min}$. Cells were then incubated with H2DCFDA $(10 \mu \mathrm{mol} / \mathrm{l})$ for $45 \mathrm{~min}$ at $37^{\circ} \mathrm{C}$ in a humidified $5 \% \mathrm{CO}_{2}$ incubator, and washed twice with PBS. Cells were finally resuspended in PBS and acquired using FACSCalibur flow cytometer. The experiment was performed in triplicates and $\mathrm{H}_{2} \mathrm{O}_{2}(1$ and $10 \mu \mathrm{g} / \mathrm{ml})$ was used as a positive inducer of ROS. Intracellular ROS levels, reflected by the mean fluorescence intensity (MFI) of 2,7-dichlorofluorescein (DCF)-stained HAEC were measured using CellQuest Pro software. HAEC were identified based on their FSC and SSC characteristics.

Statistics. GraphPad Prism software (version 6) was used to perform statistical data analysis and drawing of graphs. Data are presented as mean \pm standard error of the mean (SEM). The non-parametric Kruskal-Wallis test followed by a Dunn's multiple comparison post-hoc test was performed to determine statistical differences among the different experimental groups. $\mathrm{P}<0.05$ was considered to indicate a statistically significant difference.

\section{Results}

Expression of selected fibrinolytic genes in HAEC in response to $n L D L$ or MoxLDL treatment. A previous study has demonstrated that MoxLDL delays fibrinolysis pericellularly in EA.hy926 endothelial cells (14). Several genes such as tPA, uPA, tPA receptor (tPAR), uPA receptor (UPAR) and PAI-1 are known to be key players in the process of fibrinolysis (21). However, whether their expression levels in HAEC are altered upon MoxLDL treatment remains unknown. Therefore, we have assessed by RT-qPCR the mRNA expression profile of the above-mentioned genes in HAEC treated with nLDL or MoxLDL for $24 \mathrm{~h}$. Fibrinolysis activators, tPA and uPA, in addition to their corresponding receptors, tPAR and UPAR, did not show a significant variation in their mRNA expression levels following treatment with nLDL or MoxLDL. PAI-1 also, the major plasminogen activator inhibitor, did not show a variation in expression (Fig. 1). Finally, FXIII, a principal hemostatic factor and the protein responsible for crosslinking fibrin meshwork was found not to be expressed in HAEC (data not shown).

Effect of $n L D L$ or MoxLDL treatment on the morphology and viability of $H A E C$. HAEC were cultured in a 6-well plate and were left untreated or treated with either $100 \mu \mathrm{g} / \mathrm{ml}$ of nLDL or MoxLDL for $24 \mathrm{~h}$. The cells were then visualized under an inverted phase contrast microscope. HAEC showed a healthy morphology with no or little detached cells detected (Fig. 2). Supplementary PI staining and FACS analysis were also carried out and did not show any significant effect of MoxLDL on HAEC viability (data not shown).

Effect of $n L D L$ and MoxLDL treatment on the morphology and adherence of BAE cells. In order to study the effect of nLDL and MoxLDL on BAE cells, confluent monolayer cells were treated with $100 \mu \mathrm{g} / \mathrm{ml}$ of nLDL, and 25,50 , and $100 \mu \mathrm{g} / \mathrm{ml}$ of MoxLDL for $24 \mathrm{~h}$. Following MoxLDL treatment, a significant 
tPA

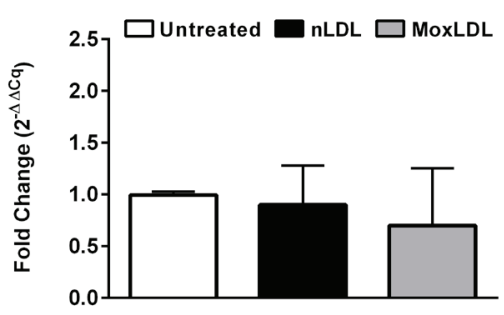

tPAR

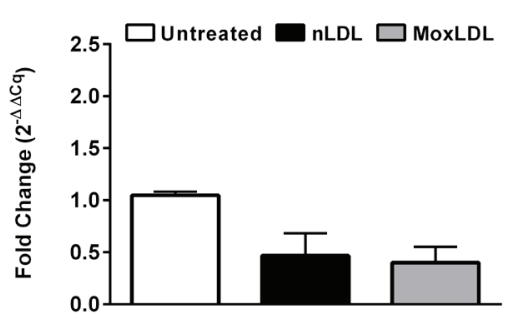

PAI-1

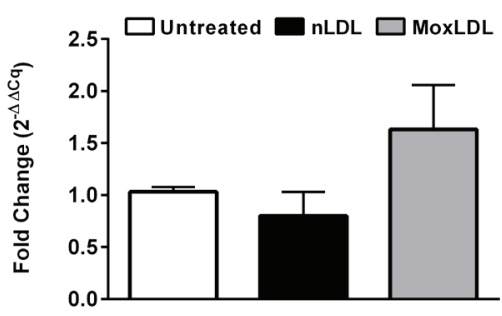

UPA
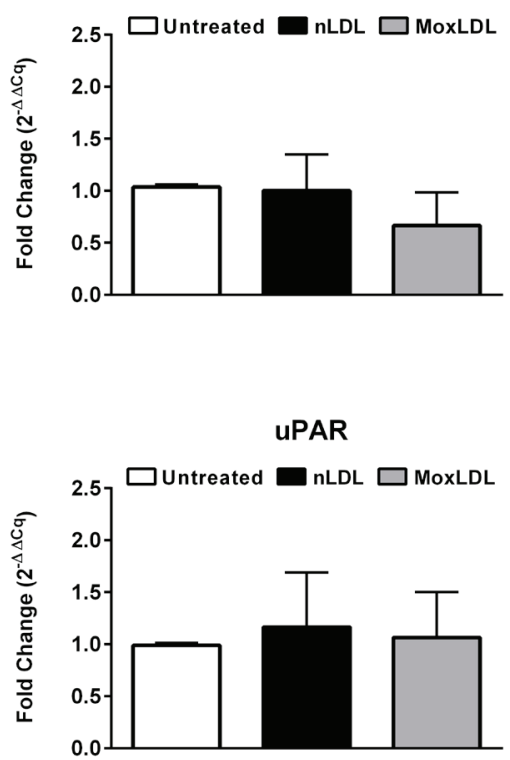

Figure 1. Relative Gene Expression of Fibrinolysis Mediators. tPA, uPA, tPAR, uPAR and PAI-1 levels in human aortic endothelial cells were determined via reverse transcription-quantitative PCR following treatment with physiological concentrations (100 $\mu \mathrm{g} / \mathrm{ml})$ of $\mathrm{nLDL}$ or MoxLDL for $24 \mathrm{~h}$. Data are presented as the mean \pm SEM $(n=3)$ fold change in mRNA expression vs. control expression (untreated cells). tPA, tissue plasminogen activator; urokinase plasminogen activator; tPAR, tPA receptor; uPAR, uPA receptor; PAI-1, plasminogen activator inhibitor-1; nLDL, native low-density lipoprotein; MoxLDL, myeloperoxidase modified low-density lipoprotein.
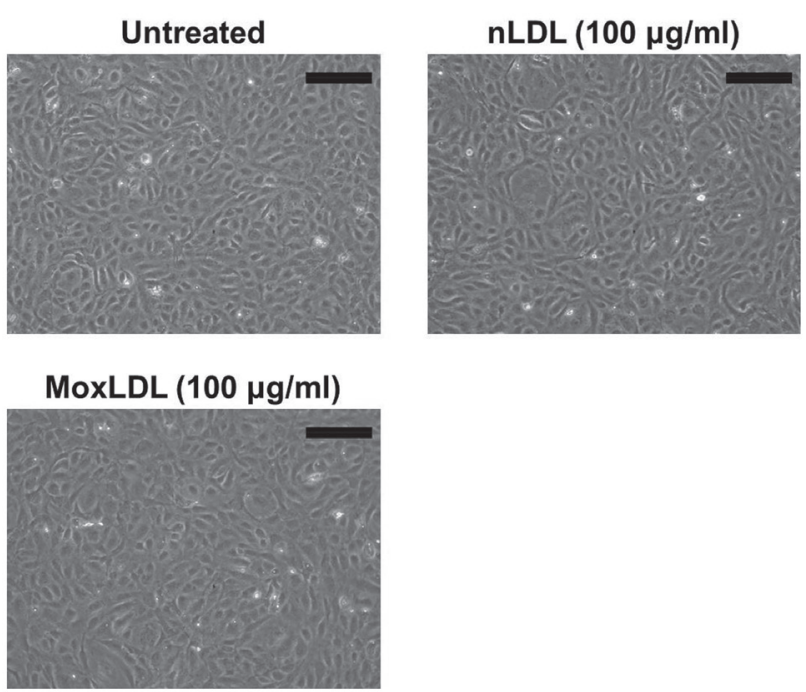

Figure 2. Morphology of HAECs following treatment with nLDL or MoxLDL. HAEC (passage 5-6) were cultured in 6-well plates and left untreated or treated with $100 \mu \mathrm{g} / \mathrm{ml} \mathrm{nLDL}$ or MoxLDL for $24 \mathrm{~h}$ (Scale bars, $100 \mu \mathrm{m})$. HAECs, human aortic endothelial cells; nLDL, native low-density lipoprotein; MoxLDL, myeloperoxidase modified low-density lipoprotein. high percentage of detached and floating cells was noted when BAE cells were visualized under an inverted phase contrast microscope. However, nLDL treatment did not induce BAE cell detachment and cells were maintained as a monolayer (Fig. 3).

Effect of $n L D L$ and MoxLDL treatment on the viability of BAE cells. We assumed that the detachment of BAE cells might be a consequence of a cytotoxic effect induced by MoxLDL treatment. Therefore, PI viability assay was performed in order to assess the cytotoxic effect of MoxLDL as well as the effect of nLDL on BAE cells. Treated BAE cells were harvested, stained with PI, and analyzed by flow cytometry. As expected, untreated cells and nLDL-treated cells showed some little extent of spontaneous cell death. However, adequate cell viability analysis of MoxLDL-treated BAE cells was not possible due to that fact that cell fragments and debris compromised the bulk of the culture (Fig. 4).

Effect of $n L D L$ or MoxLDL treatment on ROS production by $H A E C$. OxLDL has been previously reported, to increase ROS production by endothelial cells (22). Therefore, the ability of 

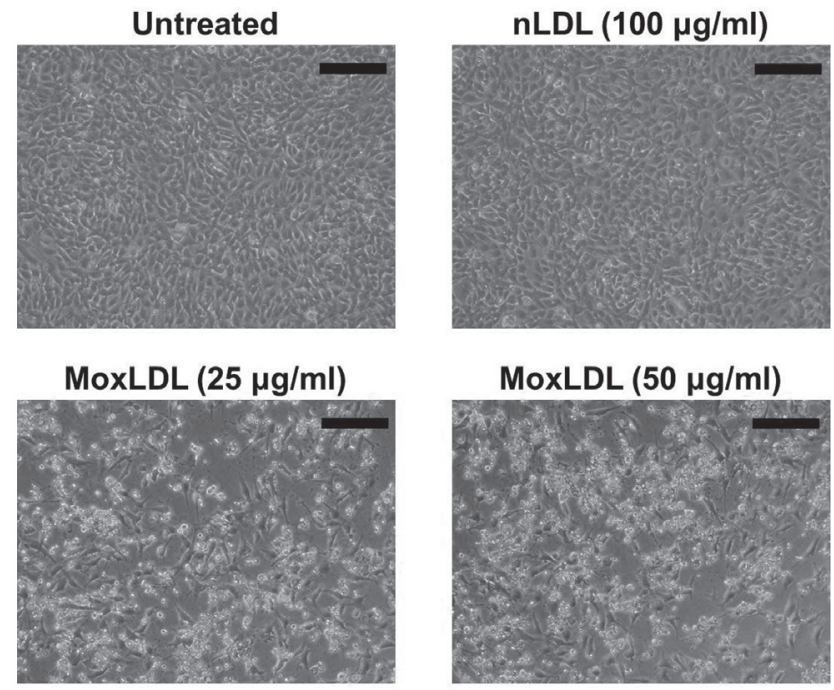

MoxLDL $(100 \mu \mathrm{g} / \mathrm{ml})$

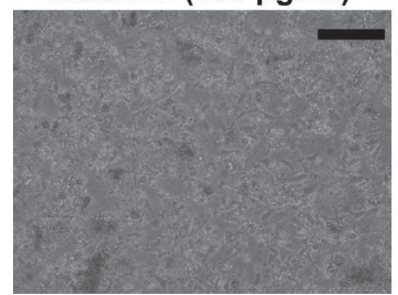

Figure 3. Effect of nLDL or MoxLDL treatment on the morphology and adherence of BAE cells. BAE cells (passage 8-9) were cultured in 12 -well plates and left untreated or treated with $100 \mu \mathrm{g} / \mathrm{ml} \mathrm{nLDL}$ or with 25, 50 and $100 \mu \mathrm{g} / \mathrm{ml}$ MoxLDL for $24 \mathrm{~h}$ (scale bars, $100 \mu \mathrm{m}$ ). nLDL, native low-density lipoprotein; MoxLDL, myeloperoxidase modified low-density lipoprotein; BAE, bovine aortic endothelial.

MoxLDL to induce endothelial cells to generate ROS was assessed by H2DCFDA staining combined with flow cytometry analysis. MoxLDL treatment resulted with no increase but in a decrease in the production of ROS as compared to untreated cells; however, this decrease did not attain statistical significance $(\mathrm{P}>0.05$; Fig. 5). Likewise, $\mathrm{nLDL}$ treatment showed a non-significant $(\mathrm{P}>0.05)$ decrease in ROS production (Fig. 5). $\mathrm{H}_{2} \mathrm{O}_{2}(1$ and $10 \mu \mathrm{g} / \mathrm{ml})$, used as a positive control, induced high and significant levels of ROS by HAEC (Fig. 5).

\section{Discussion}

In our study, the interaction between MoxLDL, endothelial cells, and mainly fibrinolysis was investigated. All previous research documented and explored the signaling pathway by which CuoxLDL initiate inflammation and subsequent atherogenesis (23). On the contrary, very little is known about the MoxLDL. MPO modified LDL is the more physiologically relevant model of LDL oxidation due to the fact that immunohistochemical analyses conducted by Daugherty et al (7) and others co-localize MPO and some modified amino acids in the ApoB100 moiety of LDL, such as chlorotyrosine or nitrotyrosine, within human atheromatous plaques $(7-9,24)$. Therefore, in our study, we aimed to examine the effect of MoxLDL on different cell models: BAE and HAEC.

BAE are primary cells derived from the aorta of cows. Previous research performed on these cells showed that
$150 \mu \mathrm{g} / \mathrm{ml}$ of MoxLDL treatment for $24 \mathrm{~h}$ was markedly cytotoxic as judged by MTT assay (25). However, this study was performed using another oxidation product of MPO, which is peroxinitrite modified LDL. Similarly, our results showed tremendous death and fragmentation of BAE cells following MoxLDL treatment (LDL modified by hypochlorus acid), even at low to normal physiological concentrations $(25,50$ and $100 \mu \mathrm{g} / \mathrm{ml})(15)$. By recurring to PI staining and FACS analysis, we unsuccessfully tried to assess the exact magnitude of MoxLDL's effect in our experimental model and that was due to the remarkable fragmentation of the cells that were difficultly sorted and in a very bad shape. Hence, our results pave the way for future investigation at this level that should be carried out using maybe lower concentrations of modified LDL in order to better characterize the mechanism of cell death. On the same note and in the context of atherosclerosis, little in vivo experimentation was conducted in animals. It was not documented that animals especially bovine develop atherosclerosis naturally. This may be due to the fact of their short life span, in comparison to humans, unique digestive and metabolic characteristics, different diet and cholesterol intake. This raises again an interesting question regarding the modification of LDL molecules in their system and whether it involves similar mechanisms that are already seen and documented in humans.

Contradictory to the effect of MoxLDL on cell death in BAE cells, previous reports confirmed that MoxLDL treatment (up to $100 \mu \mathrm{g} / \mathrm{ml}$ ) does not reduce viability or induce cell death in human endothelial cells, human umbilical Vein Endothelial Cells (HUVEC) (26). Preponderance of studies reported that uptake by LOX-1 receptor, a type of scavenger receptors minimally expressed on inactivated vascular endothelium, is involved in endothelial activation, dysfunction and subsequent initiation of atherosclerosis. It has been shown that CuoxLDL binds to LOX-1 receptor increasing transcriptional activation of LOX-1 mRNA synthesis, entering in a positive feedback loop that exacerbate the vascular dysfunction $(27,28)$. Intracellularly, this binding activates membrane bound NADPH oxidase that rapidly elevates the level of ROS by generating super oxide ion, exacerbating the inflammatory signal (29). Enough evidence had been accumulated to state that CuoxLDL stimulates ROS generation; however, very limited research was conducted on endothelial cells using MoxLDL to check the levels of ROS production. As a matter of fact, CuoxLDL is not physiologically relevant. In particular, CuoxLDL is not closely related to the oxidized LDL present in vivo. High concentrations of $\mathrm{Cu}$ or $\mathrm{Fe}$ used in vitro to oxidized LDL are never met physiologically. Several enzymes were proposed as a physiological alternative to the modification of LDL such as MPO and peroxidasin (16). Additionally, immunohistochemical and biochemical analyses conducted by Delporte et al (8) co-localize MPO and its modified amino acids products, such as chlorotyrosine or nitrotyrosine within human atheromatous plaques $(7,9,13,24)$. Also, high serum levels of MPO are regarded as a risk factor in CADs (30).

Data in the literature show MoxLDL's key involvement in the interplay and fine-tuning between the coagulation and fibrinolytic systems on the endothelial cell surface; yet little is known about the mechanism by which MoxLDL binds to the endothelium initiating the dysfunction. The endothelium 

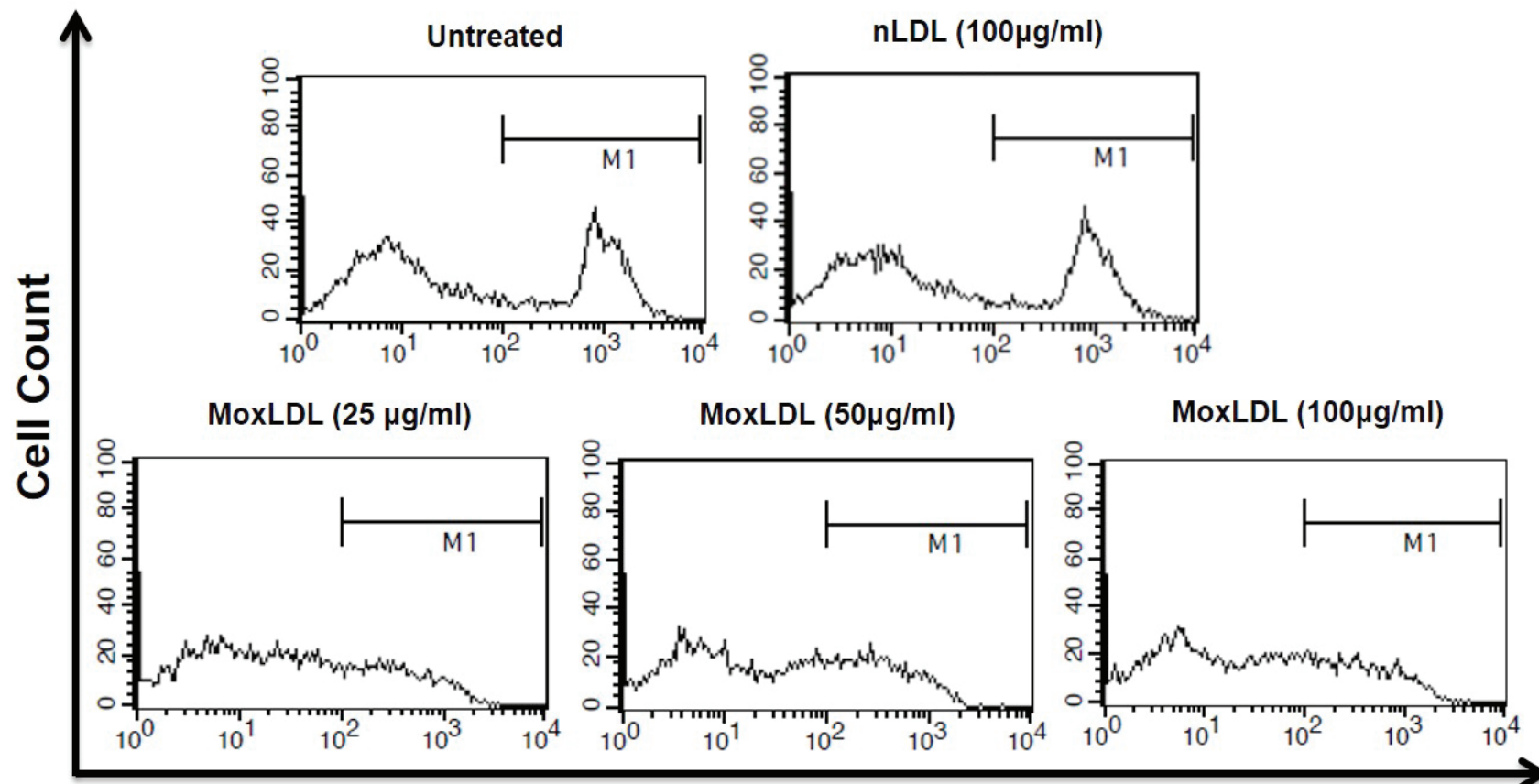

PI

Figure 4. Effect of MoxLDL Treatment on BAE Cell Viability. Representative flow cytometry histogram plots demonstrating propidium iodide (PI) staining of BAE cells that were left untreated or were treated with $100 \mu \mathrm{g} / \mathrm{ml}$ of nLDL or 25, 50, or $100 \mu \mathrm{g} / \mathrm{ml}$ MoxLDL for $24 \mathrm{~h}$. Data are representative of the experiment performed in triplicate.
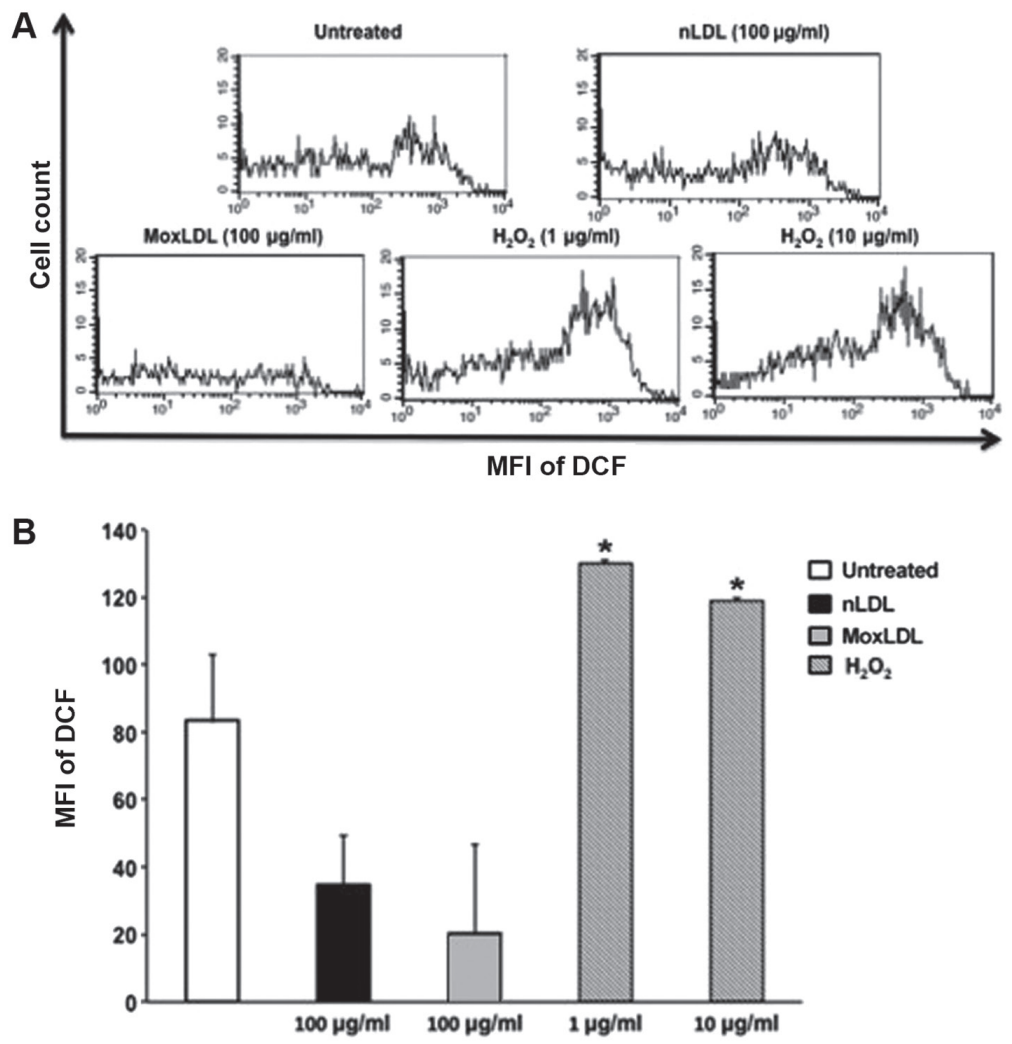

Figure 5. Effect of MoxLDL on HAEC reactive oxygen species production. HAECs (passage 5-6) were cultured in 6-well plates and left untreated or treated with $100 \mu \mathrm{g} / \mathrm{ml} \mathrm{nLDL}$, MoxLDL or $\mathrm{H}_{2} \mathrm{O}_{2}(1$ or $10 \mu \mathrm{g} / \mathrm{ml})$ for $24 \mathrm{~h}$. Cells were then harvested, labeled with $\mathrm{H}_{2}$ DCFDA and analyzed via flow cytometry. (A) Representative histogram plots demonstrating the geometric MFI of DCF-stained HAEC from different conditions. (B) Bar graph presenting the MFI values (mean $\pm \mathrm{SEM}$ ) of DCF-stained HAECs $(\mathrm{n}=3$ ). "P<0.05 vs. the control. MoxLDL, myeloperoxidase modified low-density lipoprotein; HAECs, human aortic endothelial cell; MFI, mean fluorescent intensity; DCF, 2,7-dichlorofluorescein. 
secretes tPA and $\mathrm{UPA}$, and expresses specific receptors that bind these factors supporting a fibrinolytic environment (13). Moreover, the binding of plasminogen and tPA to fibrin or their respective receptors ensures the protection from $\alpha_{2}$-antiplasmin and $\alpha_{2}$-macroglobulin inhibition. This means that endothelial cells and their receptors aid and promote pericellular fibrinolysis (31). Early evidence correlates fibrin deposition and plaque formation. Consistent with that, studies documented that fibrin deposition on endothelial cells alters their cobblestone morphology, induce the production of IL-8 and inflammatory and chemotactic molecules, and most importantly renders them more permeable to LDL infiltration (32). Due to previous technical limitations, studying the effect of MoxLDL on pericellular fibrinolysis was a challenge. However, more recently, a technical device that detects fibrinolysis in real-time was successfully created (14). In the latter model, the authors associated MoxLDL with a delayed fibrinolytic capacity of the endothelium, but no effect on PAI-1, tPA, uPAR, tPAR or plasmin inhibitors: $\alpha_{2}$-antiplasmin and $\alpha_{2}$-macroglobulin was recorded. These cells that were used in the study were hybrid cells that arise from a fusion between HUVECs and thioguanine-resistant clone of A549 human carcinoma cell line (33). In accordance with this previous finding suggesting the null transcriptional effect of MoxLDL on the fribrinolytic key players, our results verified so while using the role model of cells to study atherosclerosis: Human aortic endothelial cells (HAEC). We additionally studied another potential effector that might be the cause behind this delay: Factor XIII. Factor XIII, also known as fibrin stabilizing factor, crosslinks every E-unit with a D-unit of fibrin monomers further stabilizing the fibrin meshwork. Contradictory observations are published on the fact whether endothelial cells secrete FXIII or not (34). Our results showed that HAEC that were analyzed by RT-qPCR do not express it.

As for the negative effect of MoxLDL on pericellular fibrinolysis in endothelial cells, and since we've shown that it was not related to a change in gene expression, one potential mechanism that remains effective is the possibility of a physical interaction between MoxLDL and specific cell membrane receptors that are expressed on endothelial cells, more specifically tPAR and UPAR receptors, which can explain this delay as a competitive inhibition on the receptor itself by MoxLDL. This was seen with other pro-atherogenic molecules such as apolipoprotein (a) which was shown to bind tPAR receptors with high affinity (35).

Finally, preceding reports stated that MoxLDL lacked an effect on the expression of LOX-1 gene expression as opposed to CuoxLDL that was reported to increase LOX-1 expression $(14,36)$. This was further validated by our experiments that did not show an increase in ROS production intracellulary in HAEC (15). Therefore, it is likely that MoxLDL acts through a still undetermined receptor(s), eliciting signaling transduction pathways that are dissimilar to CuoxLDL.

This study gave interesting insights onto the effect of MoxLDL on the gene expression of central players in fibrinolysis in HAEC as well as a potentially different mechanism of action for MoxLDL as compared to CuoxLDL. In hope that our results will pave the way for more experiments, some prospective research work can be proposed including the investigation of the potential receptor(s) that is/are responsible for binding to MoxLDL. Accordingly, a series of knockdown experiments (tackling potential receptors/signaling proteins) can be conducted in order to study the signaling transduction pathway(s) promoted by MoxLDL in HAEC thus helping us reveal the key players that are responsible for the phenotype that is being uncovered after subjecting the cells to physiological levels of MPO-modified LDL.

\section{Acknowledgements}

The authors would like to thank Dr Marwan El-Sabban (American University of Beirut, Beirut, Lebanon) for his valuable help and contribution to the study by providing HAEC and BAE cell.

\section{Funding}

This present study was funded by the National Council for Scientific Research in Lebanon CNRS-L and the University of Balamand (grant no. 1849-18).

\section{Availability of data and materials}

Previously reported [expression of Selected Fibrinolytic Genes in HAEC in Response to nLDL or MoxLDL Treatment] data were used to support this study and are available at [doi: 10.1155/2014/134635-doi: 10.1371/journal.pone.0038810]. These prior studies (and datasets) are cited at relevant places within the text as references [Daher et al, 2014-Zouaoui Boudjeltia et al, 2012].

\section{Authors' contributions}

LV, KB, MK and JD conceived the current study and designed the experiments. GS and JD wrote the manuscript. JD and SB edited the manuscript. GS and SB performed data analysis.

\section{Ethics approval and consent to participate}

The CHU Charleroi Hospital Ethics Committee (Comité d'Ethique I.S.P.PC: OM008) has approved blood sampling and has specifically approved this study. The studies conform to the principles outlined in the Declaration of Helsinki.

\section{Patient consent for publication}

Not applicable.

\section{Competing interests}

The authors declare that they have no competing interests.

\section{References}

1. Mathers CD and Loncar D: Projections of global mortality and burden of disease from 2002 to 2030. PLoS Med 3: e442, 2006.

2. Lozano R, Naghavi M, Foreman K, Lim S, Shibuya K, Aboyans V, Abraham J, Adair T, Aggarwal R, Ahn SY, et al: Global and regional mortality from 235 causes of death for 20 age groups in 1990 and 2010: A systematic analysis for the global burden of disease study 2010. Lancet 380: 2095-2128, 2012. 
3. Virchow R: Gesammelte Abhandlungen zur Wissenschaftlichen Medicin (Collected treatises on scientific medicine). Meidinger Sohn \& Comp., 1856.

4. Galkina E and Ley K: Immune and inflammatory mechanisms of atherosclerosis (*). Ann Rev Immunol 27: 165-197, 2009.

5. Steinberg D, Parthasarathy S, Carew TE, Khoo JC and Witztum JL: Beyond cholesterol. Modifications of low-density lipoprotein that increase its atherogenicity. N Engl J Med 320: 915-924, 1989.

6. Hansson GK: Regulation of immune mechanisms in atherosclerosis. Ann N Y Acad Sci 947: 157-166, 2001.

7. Daugherty A, Dunn JL, Rateri DL and Heinecke JW: Myeloperoxidase, a catalyst for lipoprotein oxidation, is expressed in human atherosclerotic lesions. J Clin Invest 94: 437-444, 1994

8. Delporte C, Boudjeltia KZ, Noyon C, Furtmuller PG, Nuyens V, Slomianny MC, Madhoun P, Desmet JM, Raynal P, Dufour D, et al: Impact of myeloperoxidase-LDL interactions on enzyme activity and subsequent posttranslational oxidative modifications of apoB-100. J Lipid Res 55: 747-757, 2014.

9. Hazell LJ, Baernthaler G and Stocker R: Correlation between intima-to-media ratio, apolipoprotein B-100, myeloperoxidase and hypochlorite-oxidized proteins in human atherosclerosis. Free Radic Biol Med 31: 1254-1262, 2001.

10. Zhang R, Brennan ML, Fu X, Aviles RJ, Pearce GL, Penn MS Topol EJ, Sprecher DL and Hazen SL: Association between myeloperoxidase levels and risk of coronary artery disease. JAMA 286: 2136-2142, 2001.

11. Wobst J, Kessler T, Dang TA, Erdmann J and Schunkert H: Role of sGC-dependent NO signalling and myocardial infarction risk. J Mol Med (Berl) 93: 383-394, 2015.

12. Cesarman-Maus G and Hajjar KA: Molecular mechanisms of fibrinolysis. Br J Haematol 129: 307-321, 2005.

13. Delporte C, Van Antwerpen P, Vanhamme L, Roumeguere T and Zouaoui Boudjeltia K: Low-density lipoprotein modified by myeloperoxidase in inflammatory pathways and clinical studies. Mediators Inflamm 2013: 971579, 2013.

14. Zouaoui Boudjeltia K, Daher J, Van Antwerpen P, Moguilevsky N, Delree P, Ducobu J, Raes M, Badran B, Vanhaeverbeek M, Brohee D, et al: Exposure of endothelial cells to physiological levels of myeloperoxidase-modified LDL delays pericellular fibrinolysis. PLoS One 7: e38810, 2012.

15. El Samad G: Effect of myeloperoxidase modified LDL on bovine and human aortic endothelial cells (unpublished $\mathrm{PhD}$ thesis). University of Balamand, El Koura, 2018.

16. Colon S, Page-McCaw P and Bhave G: Role of hypohalous acids in basement membrane homeostasis. Antioxid Redox Signal 27: 839-854, 2017.

17. Livak KJ and Schmittgen TD: Analysis of relative gene expression data using real-time quantitative PCR and the 2(-Delta Delta C(T)) method. Methods 25: 402-408, 2001

18. Eisenberg T, Carmona-Gutierrez D, Büttner S, Tavernarakis N and Madeo F: Necrosis in yeast. Apoptosis 15: 257-268, 2010.

19. Ocampo A and Barrientos A: Quick and reliable assessment of chronological life span in yeast cell populations by flow cytometry. Mech Ageing Dev 132: 315-323, 2011.

20. Deere D, Shen J, Vesey G, Bell P, Bissinger P and Veal D: Flow cytometry and cell sorting for yeast viability assessment and cell selection. Yeast 14: 147-160, 1998.

21. Chapin JC and Hajjar KA: Fibrinolysis and the control of blood coagulation. Blood Rev 29: 17-24, 2015.

22. Eruslanov E and Kusmartsev S: Identification of ROS using oxidized DCFDA and flow-cytometry. Methods Mol Biol 594: 57-72, 2010.

23. Barter P: Lipoprotein metabolism and CKD: Overview. Clin Exp Nephrol 18: 243-246, 2014.
24. Sugiyama S, Okada Y, Sukhova GK, Virmani R, Heinecke JW and Libby P: Macrophage myeloperoxidase regulation by granulocyte macrophage colony-stimulating factor in human atherosclerosis and implications in acute coronary syndromes. Am J Pathol 158: 879-891, 2001.

25. Steffen Y, Schewe T and Sies H: Epicatechin protects endothelial cells against oxidized LDL and maintains NO synthase. Biochem Biophys Res Commun 331: 1277-1283, 2005.

26. Daher J, Martin M, Rousseau A, Nuyens V, Fayyad-Kazan H, Van Antwerpen P, Courbebaisse G, Martiat P, Badran B, Dequiedt F, et al: Myeloperoxidase oxidized LDL interferes with endothelial cell motility through miR-22 and heme oxygenase 1 induction: Possible involvement in reendothelialization of vascular injuries. Mediators Inflamm 2014: 134635, 2014.

27. Chen XP, Xun KL, Wu Q, Zhang TT, Shi JS and Du GH: Oxidized low density lipoprotein receptor-1 mediates oxidized low density lipoprotein-induced apoptosis in human umbilical vein endothelial cells: Role of reactive oxygen species. Vascul Pharmacol 47: 1-9, 2007.

28. Sawamura T, Kume N, Aoyama T, Moriwaki H, Hoshikawa H, Aiba Y, Tanaka T, Miwa S, Katsura Y, Kita T and Masaki T: An endothelial receptor for oxidized low-density lipoprotein. Nature 386: 73-77, 1997.

29. Neri Serneri GG, Coppo M, Bandinelli M, Paoletti P, Toscano T, Micalizzi E, Chiostri M and Boddi M: Exaggerated myocardial oxLDL amount and LOX-1 receptor over-expression associated with coronary microvessel inflammation in unstable angina. Atherosclerosis 226: 476-482, 2013.

30. Meuwese MC, Stroes ES, Hazen SL, van Miert JN, Kuivenhoven JA, Schaub RG, Wareham NJ, Luben R, Kastelein JJ, Khaw KT and Boekholdt SM: Serum myeloperoxidase levels are associated with the future risk of coronary artery disease in apparently healthy individuals: The EPIC-Norfolk prospective population study. J Am Coll Cardiol 50: 159-165, 2007.

31. Sueishi K, Ichikawa K, Kato K, Nakagawa K and Chen YX: Atherosclerosis: Coagulation and fibrinolysis. Semin Thromb Hemost 24: 255-260, 1998.

32. Qi J, Goralnick S and Kreutzer DL: Fibrin regulation of interleukin-8 gene expression in human vascular endothelial cells. Blood 90: 3595-3602, 1997

33. Ahn K, Pan S, Beningo K and Hupe D: A permanent human cell line (EA.hy926) preserves the characteristics of endothelin converting enzyme from primary human umbilical vein endothelial cells. Life Sci 56: 2331-2341, 1995.

34. Koch M and Zernecke A: The hemostatic system as a regulator of inflammation in atherosclerosis. IUBMB Life 66: 735-744, 2014.

35. Romagnuolo R, Marcovina SM, Boffa MB and Koschinsky ML: Inhibition of plasminogen activation by apo(a): Role of carboxyl-terminal lysines and identification of inhibitory domains in apo(a). J Lipid Res 55: 625-634, 2014.

36. Aoyama T, Fujiwara H, Masaki T and Sawamura T: Induction of lectin-like oxidized LDL receptor by oxidized LDL and lysophosphatidylcholine in cultured endothelial cells. J Mol Cell Cardiol 31: 2101-2114, 1999

This work is licensed under a Creative Commons Attribution-NonCommercial-NoDerivatives 4.0 International (CC BY-NC-ND 4.0) License. 